\section{Effects of Different Polishing Protocols on Lithium Disilicate Ceramics}

Tânia Mara da Silva, Ana Carolina Rodrigues Danzi Salvia, Rodrigo Furtado

de Carvalho, Eduardo Galera da Silva, Clóvis Pagani

The aim of this study was to evaluate the effect of different polishing protocols on surface roughness and morphology of lithium disilicate ceramics (IPS e.max CAD). Fifty ceramic bars $(2.0 \times 3.0 \times 2.5 \mathrm{~mm})$ were produced and randomly divided into five groups $(\mathrm{n}=10)$, according to surface treatments: C: Control; Cer: Ceramaster (60 s); CW: cloth wheel with large-grit diamond (30 s) + cloth wheel with fine-grit diamond paste (30 s); E: grey Exa-Cerapol (20 s) + pink Exa-Cerapol (20 s) + Cerapol Super (20 s); F: Felt wheel with large-grit diamond paste (30 s) + Felt wheel with fine-grit diamond paste (30 s). The samples were evaluated quantitatively for surface roughness (Ra) and qualitatively by SEM, at different moments: initial (prior to roughening), after roughening and after polishing procedures. Ra means were submitted to two-way ANOVA and Tukey test $(p<0.05)$. After the different polishing protocols, no statistically significant differences were observed between the Cer and E groups ( $p=0.6347), E$ and CW groups $(p=0.1366)$, and CW and FW groups $(p=0.5433)$. Comparing different stages in the same group, it was possible to observe that CW $(p<0.0001)$ and FW groups $(p<0.0001)$ showed significant differences. SEM analysis revealed that both Cer and E groups exhibited a surface morphological pattern similar to that of control group. All polishing systems were effective in reducing the surface roughness of the studied ceramic type.
Department of Restorative Dentistry, Institute of Science and Technology of São José dos Campos, UNESP - Universidade Estadual Paulista, São José dos Campos, SP, Brazil

Correspondence: Tânia Mara da Silva, Avenida Engenheiro Francisco José Longo, 777, Jardim São Dimas, 12245-000 São José dos Campos, SP, Brasil. Tel: +55:12:3947:9048. e:mail: taniamara.odonto@gmail.com

Key Words: ceramics, roughness surface, polishing.

\section{Introduction}

Dental ceramics are widely employed as restorative material to replace lost or damaged teeth because of their esthetic features, durability, biocompatibility and surface smoothness (1-6). The demand for successful esthetic restorations has led to the development of improved ceramic systems with better mechanic properties (4-6).

CAD/CAM dental systems were developed in the 1980's $(2,7)$. These systems used machined ceramic materials that enabled automated construction of full-ceramic restorations, decreasing the technical imprecisions and manufacturing time $(2,7)$. Among these materials, IPS e.max CAD is a machined lithium disilicate glass ceramic, developed to improve the strength of glass ceramic materials $(2,8)$. It is an excellent alternative to treatment because it allows mimicking the tooth structure (8). Lithium disilicate ceramics have been recommended to manufacture both anterior and posterior crowns, implant-supported crowns, inlays, onlays or veneers (8).

On one hand, these restorations frequently require intraoral adjustments to enable adequate occlusion, improve the esthetics and remove overhanging $(1,3,6,9-$ 11). On the other hand, adjustment procedures generally performed with fine-grit diamond burs remove the glaze layer, resulting in rough surfaces and color alteration (1014). Roughness also favors bacterial biofilm accumulation, gingivitis, periodontitis and caries $(1,10,13)$. Surface roughness can lead to loss of esthetic quality, produce patient's discomfort and generate areas of stress concentration, thus negatively affecting the material strength $(1-3,9,13)$.

Therefore, a smooth surface on dental ceramics is necessary not only for the esthetics but also for biological reasons, to improve the restoration's strength, decrease the wear of opposing teeth and increase longevity to the restored tooth $(1,5,6,13)$. Adequately performed intraoral finishing and polishing procedures are alternatives to promote clinically acceptable surface smoothness $(4,5)$. Even so, placement of restoration induces some defects that demand proper polishing, especially on areas of load support and deep fissures (5).

Many polishing protocols are available to eliminate or decrease the fissures arising during the adjustment of ceramic restorations and to achieve a smooth and resistant surface, like different grit diamond burs, sandpapers, abrasive rubber wheel, polishing stones, abrasive diamond particles or diamond pastes $(4,10,13,15,16)$.

Notwithstanding, results regarding the polishing system performance are inconsistent because of different measurement parameters and different associations of polishing methods and ceramic materials $(9,13,16)$.

Therefore this study aimed to evaluate the effect of different polishing protocols on IPS e.max CAD ceramics. The null hypotheses were: (I) the different polishing protocols will not show significant differences on surface roughness and morphology of IPS e.max CAD ceramics; 
(II) the experimental polishing protocols will not show significant differences when compared with the commercial polishing systems.

\section{Material and Methods}

The materials used in this study (brand, manufacturer, batch) are specified in Table 1.

\section{Preparation of Ceramic Specimens}

To produce IPS e.max CAD LT A3/C14 ceramic bars (Ivoclar Vivadent, Schaan, Liechtenstein), the partially crystallized blocks were cut in slices (Isomet ${ }^{\circledast} 1000$, Buehler, IL, USA), with a diamond disc $(15.2 \times 0.5 \mathrm{~mm})$ (Buehler, New York, NY, USA) at low speed (200 rpm), under copious irrigation and a $100 \mathrm{kgf}$ load. Two perpendicular cuts were made so that four equal pieces were obtained from the same block.

Fifty ceramic bars $(2.0 \times 3.0 \times 2.5 \mathrm{~mm})$ were obtained and placed in circular polisher (DP-10; Panambra, São Paulo, SP, Brazil) for polishing with 2000-grit silicon carbide paper discs (Extec Corp., Enfield, CT, USA) at 300 rpm, under water cooling. Next, the bars were placed in a ceramic oven (EP5000; Ivoclar Vivadent) for crystallization. The maximum crystallization temperature was $840^{\circ} \mathrm{C}(1544$ $\left.{ }^{\circ} \mathrm{F}\right)$, as recommended by the manufacturer.

All ceramic specimens were randomly divided into five groups ( $n=10)$, according to the surface treatments (Table 2).

\section{Sample Preparation}

The ceramic bars were initially embedded in polyvinylchloride (PVC) cylinders $(2.5 \mathrm{~mm}$ diameter and $2.2 \mathrm{~mm}$ high) filled with self-curing acrylic resin (Jet Clássico, Campo Limpo Paulista, SP, Brazil) to standardize the treatments and evaluations. First, the surfaces were roughened in circular polisher (DP-10, Panambra) with 80-grit sandpaper discs (Erios Equipamentos Técnicos e Científicos Ltda., São Paulo, SP, Brazil) under water cooling, with a $500 \mathrm{gload}$, at $600 \mathrm{rpm}$ for $2 \mathrm{~min}$, to mimic the clinical post-adjustment conditions. Next, the sample surfaces were cleaned in a sonic bath with distilled water for 5 min.

Table 1. Material, brand, manufacturer and batch

\begin{tabular}{lcc}
\hline Material & Brand & Manufacturer \\
\hline Ceramics & IPS e.max CAD & lvoclar Vivadent, Schaan, Liechtenstein \\
Sandpaper discs 2000:grit & Oxi Thunder, São Paulo, SP, Brazil \\
Sandpaper discs 80 grit & Natural wool felt wheel & $\begin{array}{c}\text { Erios, Equipamentos Técnicos e } \\
\text { Científicos Ltda., São Paulo, SP, Brazil }\end{array}$ \\
Felt wheel & - & TDV Dental LTDA, Pomerode, SC, Brazil \\
Diamond cloth wheel $(2$ and $0.5 \mu \mathrm{m}$ cubic boron nitride) & - & Experimental \\
Medium-grit diamond paste $(2 \mu \mathrm{m}$ cubic boron nitride) & - & Experimental \\
Fine-grit diamond paste $(0.5 \mu \mathrm{m}$ cubic boron nitride) & Experimental \\
Polishing rubber & Pink Exa-Cerapol - torpedo & Edenta AG Dentalprodukte, Au, Switzerland \\
Polishing rubber & Cerapol Super - torpedo & Edenta AG Dentalprodukte, Au, Switzerland \\
Polishing rubber & CeraMaster - torpedo & Shofu lnc., Kyoto, Japan \\
Polishing rubber & Edenta AG Dentalprodukte, Au, Switzerland \\
\hline
\end{tabular}

Table 2. Groups and polishing protocols

\begin{tabular}{lc}
\hline Groups & Polishing protocol \\
\hline Control & No treatment \\
Cer & CeraMaster polishing rubber $(60 \mathrm{~s})$ \\
CW & Cloth wheel with large-grit diamond paste $(30 \mathrm{~s})+$ diamond cloth wheel with fine-grit diamond paste (30 s) \\
E & Grey Exa-Cerapol polishing rubber $(20 \mathrm{~s})+$ pink Exa:Cerapol polishing rubber $(20 \mathrm{~s})+$ Cerapol Super polishing rubber (20 s) \\
FW & Felt wheel with large-grit diamond paste $(30 \mathrm{~s})+$ felt wheel with fine-grit diamond paste (30 s) \\
\hline
\end{tabular}

C: Control; Cer: Ceramaster (60 s); CW: cloth wheel with large-grit diamond (30 s) + cloth wheel with fine-grit diamond paste (30 s); E: grey Exa:Cerapol (20 s) + pink Exa:Cerapol (20 s) + Cerapol Super (20 s); F: Felt wheel with large-grit diamond paste (30 s) + Felt wheel with fine-grit diamond paste (30 s). 
In the experimental groups (CW and FW), 15\% of diamond was added into the polishing paste; in the felt wheel, a medium viscosity epoxy adhesive was also used.

A single examiner performed all the polishing protocols with a low-speed handpiece at a constant pressure of $500 \mathrm{~g}$, totalizing $60 \mathrm{~s}$ of polishing procedure. After each polishing protocol, the samples were cleaned again in sonic bath with distilled water for $5 \mathrm{~min}$.

\section{Quantitative Analysis of Superficial Roughness}

At every sample preparation stage, sonic bath was performed to enable better measurement of the surface roughness profile.

Mean superficial roughness (Ra) was evaluated with a profilometer (MaxSurf XT 20; Mahr, Goettingen, Germany) initially (before roughening), after roughening and after polishing. At every measuring moment, the samples were submitted to three measurements $0.25 \mathrm{~mm}$ apart, at a 0.1 $\mathrm{mm} / \mathrm{s}$ speed on the long axis of the sample, to obtain a final mean.

Data were submitted to statistical analysis using the computer software GraphPad Prism Inc. 6.01 (San Diego, CA, USA). The inferential statistics consisted of two-way ANOVA and Tukey's test. The level of significance was set at $5 \%(p<0.05)$.

\section{Qualitative Analysis of Superficial Morphology}

To better characterize the superficial morphological pattern, two samples of each group had their surfaces analyzed in scanning electronic microscopy (SEM): initially (before roughening), after roughening and after polishing.

\section{Results}

The surface roughness analysis revealed that all groups exhibited a similar roughness pattern $(p>0.05)$ both at initial and post-roughening moments ( $p>0.05)$. After different polishing protocols, no significant differences were observed between Cer and E groups ( $p=0.6347)$, E and CW groups ( $p=0.1366)$, and CW and FW groups ( $p=0.5433)$ (Table 3). Comparing the different stages in the same group, it was observed that $\operatorname{Cer}(p=0.9738)$ and $E(p=0.8414)$ groups did not show significant differences between initial and post-polishing roughness surface. CW $(p<0.0001)$ and FW groups $(p<0.0001)$ exhibited significant differences.

SEM analysis confirmed the roughness findings, where Cer and E groups exhibited a morphological pattern similar to that of control group and CW and FW groups showed a morphological pattern with smoother fissures than those of control group (Fig. 1).

\section{Discussion}

This study evaluated the effect of four different polishing methods on the surface roughness of IPS e.max CAD ceramics. The study's null hypotheses were accepted because no differences were found among the polishing protocols applied and between the commercial and experimental polishing protocols.

The surface roughness can be measured by using either a rugosimeter or a profilometer (quantitative method) that allowed obtaining different measurement patterns. Mean surface roughness ( $R a$ ) is one of these parameters used by the authors who evaluated the effect of different polishing protocols on ceramics (16). This parameter describes the surface texture and may be defined as the arithmetic mean of all absolute distances of the profile in the measurement length (16-18).

The individual statistics of this study's groups showed that the initial surface roughness means ranged from 0.08-0.10 $\mu \mathrm{m}$, while after roughening it increased $0.4 \mu \mathrm{m}$ in all groups. After the polishing protocols, the superficial roughness means ranged from 0.08 to $0.29 \mu \mathrm{m}$ depending on the applied protocol. Ra values were close to the 0.2 $\mu \mathrm{m}$ cut-off values suggested by Bollen et al. (19) as the threshold to favor biofilm accumulation.

Concerning assessment of the superficial roughness mean values obtained by the polishing protocols, the smoothest surface was obtained by Cer and E polishing devices. Both experimental groups, comprising felt wheel (FW) and cloth wheel (CW) with diamond pastes showed values lower than those after roughening. However, these groups obtained the highest superficial roughness values among all tested polishing protocols.

SEM analysis was used to complement the quantitative analysis of surface roughness. Although the mean values of Cer and E groups were statistically similar, these groups

Table 3. Mean roughness $(\mathrm{Ra}) \pm$ standard deviation for experimental conditions

\begin{tabular}{lccc}
\hline \multirow{2}{*}{ Protocol } & \multicolumn{3}{c}{ Mean roughness $(\mathrm{Ra}) \pm$ standard deviation } \\
\cline { 2 - 4 } & Initial & After roughening & After polishing \\
\hline Control & $0.093 \pm 0.024 \mathrm{Aa}$ & $0.447 \pm 0.127 \mathrm{Ab}$ & $:$ \\
Cer & $0.090 \pm 0.069 \mathrm{Aa}$ & $0.437 \pm 0.139 \mathrm{Ab}$ & $0.080 \pm 0.067 \mathrm{Aa}$ \\
$\mathrm{CW}$ & $0.088 \pm 0.021 \mathrm{Aa}$ & $0.412 \pm 0.179 \mathrm{Ab}$ & $0.254 \pm 0.108 \mathrm{BCc}$ \\
E & $0.106 \pm 0.054 \mathrm{Aa}$ & $0.452 \pm 0.109 \mathrm{Ab}$ & $0.111 \pm 0.053 \mathrm{ABa}$ \\
FW & $0.087 \pm 0.013 \mathrm{Aa}$ & $0.424 \pm 0.116 \mathrm{Ab}$ & $0.293 \pm 0.109 \mathrm{Cc}$ \\
\hline
\end{tabular}

C: Control; Cer: Ceramaster (60 s); CW: cloth wheel with large-grit diamond (30 s) + cloth wheel with fine-grit diamond paste (30 s); E: grey Exa-Cerapol (20 s) + pink Exa-Cerapol (20 s) + Cerapol Super (20 s); F: Felt wheel with large-grit diamond paste (30 s) + Felt wheel with fine-grit diamond paste (30 s). Uppercase letters in columns and lowercase letters in rows indicate statistically significant difference statistically significant differences. 
exhibited different topographic patterns (Fig. 1). Visually, Cer group showed a better topographic profile than E group, with smaller surface irregularities. Concerning to FW and $\mathrm{CW}$ experimental groups, differences in the topographic profiles were seen in both groups. Reduction in the surface roughness occurred both in CW and FW regarding the profile after roughening. Notwithstanding, both groups exhibited greater roughness in the topographic profile compared with the initial values in Cer and $\mathrm{E}$ groups.

For a single type of ceramic and with all standardized stages in the experimental conditions, Cer and E groups did not present statistically significant differences between each other, showing a slight difference regarding the topographic profile. Accordingly, the literature has advised that the quantitative analysis of superficial roughness should be followed by a qualitative SEM analysis because even statistically similar procedures may have different topographic patterns (20), as demonstrated by the results of the present study.

Surface roughness of the material varies according to the employed methods and the used materials and instruments. Attempting to return the surface smoothness to the roughened ceramics, many polishing systems are commercially available, including: cups, discs, and brushes covered with different particles associated with different polishing paste types (16). The literature has shown that diamond polishing pastes may improve superficial smoothness $(14,21,22)$. However, in this study, groups using diamond pastes with different granulations (CW and FW groups) showed the highest Ra values.

Moreover, the particle size has a fundamental role in the topographic result of ceramic materials, in which the smallest particle size enabled a better final polishing (23). According to the results of the present study, it was also observed that materials containing the smallest diamond particles were those that promoted the smallest surface roughness values.

The CeraMaster polishing kit (Shofu) is composed by silicon covered with $6 \mu \mathrm{m}$ diamond particles, while the manufacturer of Exa-Cerapol polishing kit (Edenta) does not provide information on diamond particle sizes; and the experimental polishing kits had particle sizes ranging from 2.0 to $0.5 \mu \mathrm{m}$. Thus, the greater effectiveness of Cer group could be related to the composition of abrasive points and the percentage of diamond particles. The result of this study corroborates the finding of Wang et al. (11), in which CeraMaster polishing point produced a superficial smoothness similar to that of re-glazed surface.

Both the structure and the mechanical properties are closely related to polishing effectiveness of dental ceramics.
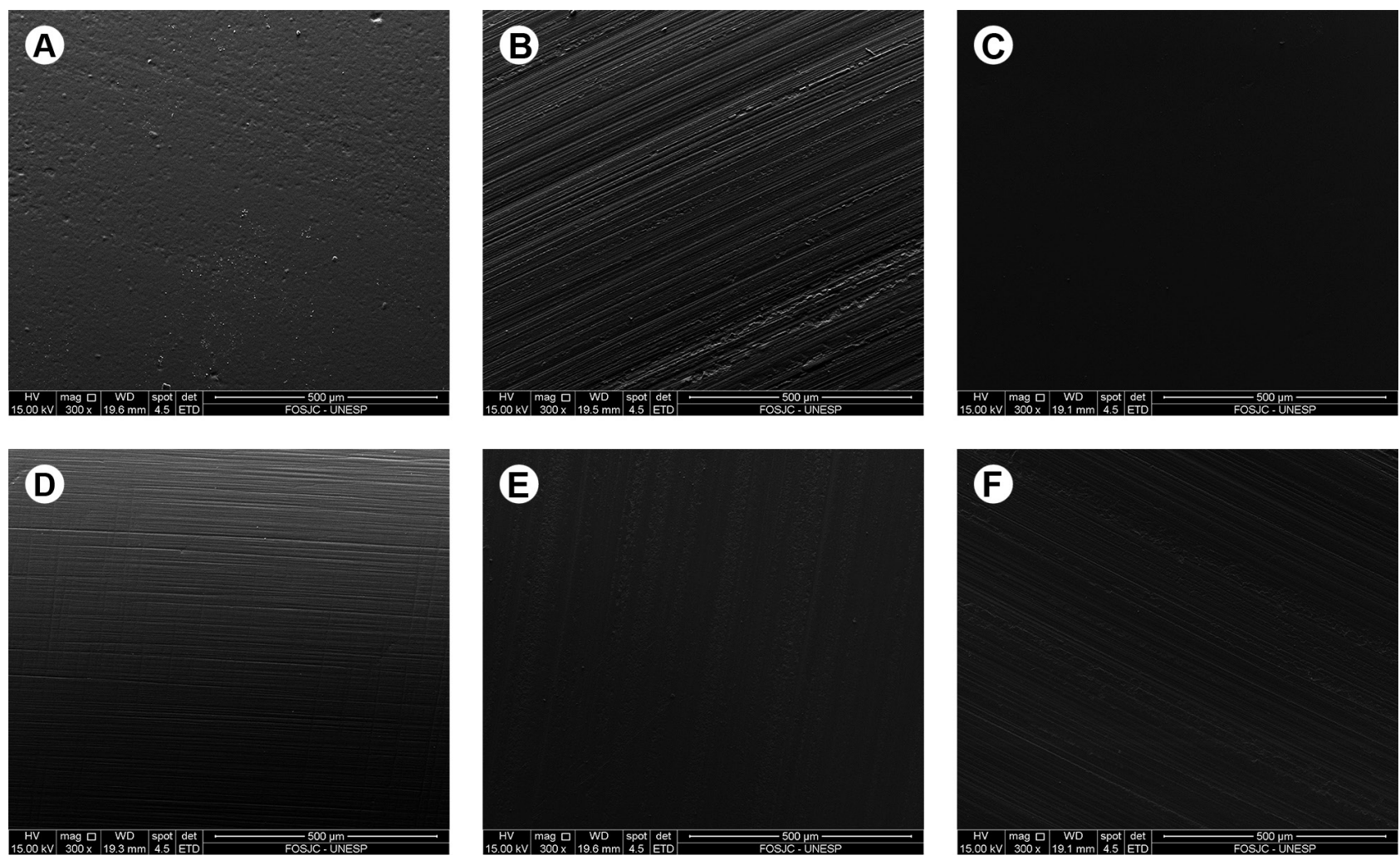

Figure 1: Superficial morphological pattern (300x): A: Initial; B: After roughening (control); C: After Cer polishing; D: After CW polishing; E: After E polishing; F: After FW polishing. 
After the rupture of the glass layer by adjustment of the restoration, the best finishing and polishing choice will depend on the used ceramics (16). In the present study, was chosen a lithium disilicate ceramic because it is composed by a partially crystalized glass obtained from the controlled growth and nucleation of crystals at vitreous phase. Glass ceramics are those which better mimic the optical properties of both enamel and dentin. The great applicability of this ceramic subtype is one of the factors that support its study. These ceramics exhibit remarkable mechanical properties and have been indicated for veneers, inlays, onlays, full crowns, three-unit fixed partial dentures at anterior and pre-molar regions $(24,25)$.

Some adjustments (occlusal or proximal) may be necessary on ceramic restorations after cementation and glazing procedure, to correct inadequate overhanging or improve esthetics $(11,17)$. These adjustments are generally performed with fine-grit diamond points that may result in glaze loss, consequently increasing the surface roughness (21). In this study, occlusal adjustment simulation was performed with sandpaper discs, resulting in surface roughening and increased superficial roughness of the samples. be submitted to a polishing protocol because superficial quality is a very important factor for clinical success of the restoration. Given the above, it is possible to consider the use of abrasive rubber points as the most effective polishing protocol that could minimize possible clinical failures. Further studies are required to confirm these findings.

Based on the results of this present study, it was observed that all polishing systems were effective in reducing the surface roughness of lithium disilicate ceramics (IPS e.max CAD). However, CeraMaster rubber point (Cer) was able to re-establish an adequate superficial smoothness in comparison with the initial surface; Exa-Cerapol rubber point (E) exhibited an intermediary behavior and the experimental groups (felt and cloth wheels with diamond pastes) obtained the highest surface roughness values among all tested polishing protocols.

\section{Resumo}

0 objetivo deste estudo foi avaliar o efeito de diferentes protocolos de polimento sobre a rugosidade e morfologia superficial de uma cerâmica à base de dissilicato de lítio (IPS e.max CAD). Foram confeccionadas 50 barras cerâmicas $(2,0 \times 3,0 \times 2,5 \mathrm{~mm})$, separadas aleatoriamente em cinco grupos $(n=10)$, conforme os tratamentos de superficie: C: Controle; $B C$ : Borracha Ceramaster (60 s); RP: Roda de pano impregnado granulação grossa (30 s) + Roda de pano impregnado granulação fina (30 s); BE: Borracha Exa-Cerapol cinza (20 s) + Borracha Exa-Cerapol rosa (20 s) + Borracha Cerapol Super (20 s); RF: Roda de feltro com pasta diamantada grossa (30 s) + roda de feltro com pasta diamantada fina (30 s). As amostras foram avaliadas quantitativamente quanto à rugosidade superficial (Ra) e qualitativamente em MEV, em diferentes momentos: inicialmente (antes da asperização), após asperização e após os polimentos. As médias de Ra foram submetidas aos testes estatisticos ANOVA (two-way) e Tukey $(p<0,05)$. Após os diferentes protocolos de polimento, não foi possivel observar diferenças significativas entre os grupos $B C$ e $B E(p=0,6347)$, entre $B E$ e $R P(p=0,1366)$ e RP e RF $(p=0,5433)$. Comparando as diferentes etapas de um mesmo grupo foi possível observar que os grupos $\mathrm{RP}(p<0,0001)$ e RF $(p<0,0001)$ apresentaram diferenças significativas. Em MEV, os grupos BC e BE apresentam um padrão morfológico superficial semelhante ao grupo controle. Todos os sistemas de polimento foram efetivos na redução da rugosidade de superfície para o mesmo padrão de cerâmica.

\section{References}

1. Al-Shammery HA, Bubb NL, Youngson CC, Fasbinder DJ, Wood DJ. The use of confocal microscopy to assess surface roughness of two milled CAD-CAM ceramics following two polishing techniques. Dent Mater 2007;23:736-741.

2. Asai T, Kazama R, Fukushima M, Okiji T. Effect of overglazed and polished surface finishes on the compressive fracture strength of machinable ceramic materials. Dent Mater J 2010;29:661-667.

3. Dalkiz M, Sipahi C, Beydemir B. Effects of six surface treatment methods on the surface roughness of a low-fusing and an ultra lowfusing feldspathic ceramic material. J Prosthodont 2009;18:217-222.

4. Karan S, Toroglu MS. Porcelain refinishing with two different polishing systems after orthodontic debonding. Angle Orthod 2008;78:947-953.

5. Lohbauer U, Muller FA, Petschelt A. Influence of surface roughness on mechanical strength of resin composite versus glass ceramic materials. Dent Mater 2008;24:250-256.

6. Nakamura Y, Sato H, Ohtsuka M, Hojo S. Polishing of dental porcelain by polycrystalline diamond. Biomed Mater Eng 2010;20:283-293.

7. Giannetopoulos $S$, van Noort R, Tsitrou E. Evaluation of the marginal integrity of ceramic copings with different marginal angles using two different CAD/CAM systems. J Dent 2010;38:980-986.

8. Fasbinder DJ, Dennison JB, Heys D, Neiva G. A clinical evaluation of chairside lithium disilicate CAD/CAM crowns: a two-year report. J Am Dent Assoc 2010;141 Suppl 2:10S-14S.

9. Albakry M, Guazzato M, Swain MV. Effect of sandblasting, grinding, polishing and glazing on the flexural strength of two pressable allceramic dental materials. J Dent 2004;32:91-99

10. Aykent F, Yondem I, Ozyesil AG, Gunal SK, Avunduk MC, Ozkan S. Effect of different finishing techniques for restorative materials on surface roughness and bacterial adhesion. J Prosthet Dent 2010;103:221-227.

11. Wang $F$, Chen JH, Wang $H$. Surface roughness of a novel dental porcelain following different polishing procedures. Int J Prosthodont 2009;22:178-180.

12. Ahmad R, Morgano SM, Wu BM, Giordano RA. An evaluation of the effects of handpiece speed, abrasive characteristics, and polishing load on the flexural strength of polished ceramics. J Prosthet Dent. 2005;94:421-429.

13. Flury S, Lussi A, Zimmerli B. Performance of different polishing techniques for direct CAD/CAM ceramic restorations. Oper Dent 2010;35:470-481.

14. Sarac D, Sarac YS, Yuzbasioglu E, Bal S. The effects of porcelain polishing systems on the color and surface texture of feldspathic porcelain. J Prosthet Dent 2006;96:122-128.

15. Karayazgan B, Atay A, Saracli MA, Gunay Y. Evaluation of Candida albicans formation on feldspathic porcelain subjected to four surface treatment methods. Dent Mater J 2010;29:147-153.

16. Silva TM, Salvia AC, Carvalho RF, Pagani C, Rocha DM, Silva EG. Polishing for glass ceramics: which protocol? J Prosthodont Res 2014;58:160-170.

17. Sarikaya I, Guler AU. Effects of different polishing techniques on the surface roughness of dental porcelains. J Appl Oral Sci 2010;18:10-16.

18. Whitehead SA, Shearer AC, Watts DC, Wilson NH. Comparison of methods for measuring surface roughness of ceramic. J Oral Rehabil 1995;22:421-427.

19. Bollen CM, Lambrechts $P$, Quirynen $M$. Comparison of surface roughness of oral hard materials to the threshold surface roughness for bacterial plaque retention: a review of the literature. Dent Mater 1997;13:258-269. 
20. Bottino MC, Valandro LF, Kantorski KZ, Bressiani JC, Bottino MA. Polishing methods of an alumina-reinforced feldspar ceramic. Braz Dent J 2006;17:285-289.

21. Sasahara RM, Ribeiro FC, Cesar PF, Yoshimura HN. Influence of the finishing technique on surface roughness of dental porcelains with different microstructures. Oper Dent 2006;31:577-583.

22. Steiner R, Beier US, Heiss-Kisielewsky I, Engelmeier R, Dumfahrt $H$, Dhima M. Adjusting dental ceramics: An in vitro evaluation of the ability of various ceramic polishing kits to mimic glazed dental ceramic surface. J Prosthet Dent 2015;113:616-622.

23. Wright MD, Masri R, Driscoll CF, Romberg E, Thompson GA, Runyan DA. Comparison of three systems for the polishing of an ultra-low fusing dental porcelain. J Prosthet Dent 2004:92:486-490.

24. Pekkan G, Hekimoglu C. Evaluation of shear and tensile bond strength between dentin and ceramics using dual-polymerizing resin cements. J Prosthet Dent 2009;102:242-252

25. Fabianelli A, Pollington S, Papacchini F, Goracci C, Cantoro A, Ferrari $M$, et al.. The effect of different surface treatments on bond strength between leucite reinforced feldspathic ceramic and composite resin. J Dent 2010;38:39-43.

Received December 4, 2014 Accepted July 20, 2015 